\title{
EFFECT OF HELICOBACTER PYLORI INFECTION ON NON VARICEAL BLEEDING IN PATIENTS WITH LIVER CIRRHOSIS
}

\author{
By \\ Samy Mohamed El-Sayed, Nader Farid Mostafa and Abdallah Hendawi \\ El-Shahat \\ Department of Hepatology, Gastroenterology and Infectious Diseases, Faculty of \\ Medicine, Al-Azhar University \\ Corresponding author: Samy Mohamed El Sayed, \\ Mobile: 01068771916, E-mail: n.eraa7666@yahoo.com
}

\begin{abstract}
Background: Variceal bleeding in chronic liver disease has been studied extensively. However, 30-40\% of upper digestive hemorrhages in cirrhotic patients are non variceal (NVUGIB). Clinical features and endoscopic findings of this population have rarely been reported.

Objective: To determine the prevalence of $\mathrm{H}$. pylori infection in cirrhotic patients with non variceal upper gastrointestinal bleeding.

Patients and methods: This was carried out at Hepatology, Gastroenterology and Infectious Diseases Department of Al-Azhar University Hospitals, and conducted on 150 patients infected by H. pylori From May 2019 till November 2019.

Pateints were selected and divided into three equal groups: Group A: Patients with recent active bleeding (maximum within two days) of non variceal origin diagnosed endoscopically. Group B Matched cirrhotic patients without history of upper gastrointestinal bleeding, and group C Non-cirrhotic patients without history of upper gastrointestinal bleeding. Upper GI Endoscopy was done for all patients of the studied groups. Multiple biopsies were taken and H.pylori infection was determined by Histopathology.

Results: The mean age of participants was 54.3 years. Males were $79(52.6 \%)$ while females were 71 (47.3\%). 58 of 150 patients $(38.6 \%)$ were positive for $\mathrm{H}$. pylori. there was no significant relation between $\mathrm{H}$. pylori positivity and cause of cirrhosis. there was significant relation between H. pylori positivity and Sex of the studied cases. And there was high significant difference between the studied groups as regard H. pylori distribution.

Conclusion: There was significant association between $H$. pylori infection and non variceal upper gastrointestinal bleeding. Eradication therapy has a role in reducing the incidence of NVUGIB in cirrhotic patients.
\end{abstract}

Keywords: Cirrhosis, H. Pylori, Non Variceal, Hepatology, Gastroenterology and Infectious diseases.

\section{INTRODUCTION}

Gastrointestinal bleeding is a major cause of hospital admission, morbidity, and mortality in patients with liver cirrhosis. It is caused by various etiologies such as portal hypertension related as bleeding gastroesophageal varices, bleeding portal hypertensive gastropathy (PHG), portal hypertension-related intestinal and colonic lesions, and nonportal hypertension-related causes such as 
bleeding peptic ulcer either Helicobacter pylori related or not (Holland et al., 2015).

PHG is characterized by gastric epithelial changes with minimal inflammation and occurs in patients with liver cirrhosis with portal hypertension or those with noncirrhotic portal hypertension. The prevalence of PHG in patients with portal hypertension has been reported to vary between 20 and $80 \%$, and the incidence of acute upper gastrointestinal tract bleeding from PHG varies widely (2-12\%) (Toyonaga and Iwao, 2013).

Several pathophysiological mechanisms of PHG included the presence of Helicobacter pylori (H. pylori) infection (Hassan et al., 2018).

Knowledge of the prevalence of infection by $\mathrm{H}$. pylori in patients with liver cirrhosis and the study of the association with PHG could be useful to better understand the pathogenesis of PHG and the evaluation of possible additive effect on production of $\mathrm{PHG}$ (Pogorzelska et al., 2017).

The prevalence of non variceal bleeding in patients with liver cirrhosis increases compared with that in the general population, suggesting that factors such as congestive gastropathy associated with portal hypertension, impaired mucus and bicarbonate secretion and reduced mucosal prostaglandin levels may increase the risk to develop a gastric lesion (Kitano and Dolgor, 2012).

Although Helicobacter pylori are the major cause of peptic ulcers, the pathogenesis of ulcer disease in cirrhosis is unclear. Several studies have reported a relationship between $\mathrm{H}$ pylori and peptic ulcer in this population (Narayanan et al., 2018). Male sex and $\mathrm{H}$ pylori seropositivity are significantly related to peptic ulcer disease in cirrhotic patients (Voulgaris et al., 2019).

The present study aimed to determine the prevalence of $\mathrm{H}$. pylori infection in cirrhotic patients with non variceal upper gastrointestinal bleeding.

\section{PATIENTS AND METHODS}

This was carried out at Hepatology, Gastroenterology and Infectious Diseases Department of Al-Azhar University Hospitals, and conducted on 150 patients infected by H. pylori from May 2019 till November 2019.

\section{In this study we divided 150 patients into 3 equal groups:}

Group A (case group): Patients with recent active bleeding (maximum within two days) of non variceal origin diagnosed endoscopcally, group B (control group): Matched cirrhotic patients without history of upper gastrointestinal bleeding, and group C (Negative group): Non-cirrhotic patients without history of upper gastrointestinal bleeding. This study was performed on Systematic random sampling.

All patients were exposed to: clinical assessment, laboratory assessment: (complete blood picture, liver profil, renal function tests, pregnancy test (for females). alpha Feto protein (AFP), CEA, CA19,9, and random blood sugar (RBS) level, abdominal ultrasonographic examination for the liver, portal and splenic vein, splenic size, ascites, and abdominal masses, Fibroscan: (transient 
elastography), and upper GI Endoscopy was done for all patients of the studied groups. H.pylori infection status was determined by Histopathology.

\section{Ethical Considerations:}

Permission was obtained from the Committee of Hepatology, Gastroenterology and Infectious diseases Department and Committee of Faculty of Medicine at Al-Azhar university, and then by the ethical committee at Al-Azhar university. An informed verbal consent from every participant was taken and confidentiality of information was assured.

\section{Statistical analysis:}

Analysis of data was done using Statistical Package for the Social Sciences version 20 (SPSSInc., Chicago, IL, USA). Quantitative variables were described in the form of mean and standard deviation. Qualitative variables were described as number and percent. In order to compare parametric quantitative variables between the groups, one way ANOVA test was performed. Qualitative variables were compared using chi-square (X2) test. Pearson correlation coefficients were used to assess the association between two normally distributed variables. A $\mathrm{P}$ value $\leq 0.05$ was considered significant.

\section{RESULTS}

In this study, the age range of participants was 33 to 74 years with a mean of $54.3 \pm 10.1$ years. Males were 79 $(52.6 \%)$ while females were $71(47.3 \%)$.
There was no statistical significant difference between the studied groups as regard age and gender (Table 1).

Table (1): Demographic data in between the studied groups

\begin{tabular}{|c|c|c|c|c|c|c|c|}
\hline Groups & \multicolumn{2}{|c|}{$\begin{array}{c}\text { Group } 1 \\
\mathbf{N}=50\end{array}$} & \multicolumn{2}{|c|}{$\begin{array}{c}\text { Group } 2 \\
\mathbf{N}=50\end{array}$} & \multicolumn{2}{|c|}{$\begin{array}{c}\text { Group } 3 \\
\mathbf{N}=50\end{array}$} & $P$ value \\
\hline \multicolumn{8}{|c|}{ Age: (years): } \\
\hline $\begin{array}{l}\text { Mean } \pm \text { SD } \\
\text { Range }\end{array}$ & \multicolumn{2}{|c|}{$\begin{array}{c}55.15 \pm 10.1 \\
(35-74)\end{array}$} & \multicolumn{2}{|c|}{$\begin{array}{c}52.66 \pm 10.73 \\
(33-74)\end{array}$} & \multicolumn{2}{|c|}{$\begin{array}{c}55.10 \pm 8 \\
(35-74)\end{array}$} & $\begin{array}{c}0.342 \\
\text { (NS) }\end{array}$ \\
\hline & No. & $\%$ & No. & $\%$ & No. & $\%$ & P value \\
\hline \multicolumn{8}{|l|}{ Gender: } \\
\hline Female & 23 & 46.0 & 24 & 48.0 & 21 & 42.0 & 0.828 \\
\hline Male & 27 & 54.0 & 26 & 52.0 & 29 & 58.0 & (NS) \\
\hline
\end{tabular}

$\mathrm{F}$ wes for one way ANOVA, X2 for chi square test. 
There was no significant relation between $H$. pylori positivity and Child
Pugh score of the studied cirrhotic cases (Table 2).

Table (2): Relation between H. pylori positivity and Child Pugh score of the studied cirrhotic cases

\begin{tabular}{|c|c|c|c|c|c|}
\hline \multirow{2}{*}{ Variables } & \multicolumn{2}{|c|}{$\begin{array}{c}\text { H.pylori -ve cases } \\
\qquad \begin{array}{c}\mathrm{N}=50\end{array}\end{array}$} & \multicolumn{2}{|c|}{$\begin{array}{c}\text { H.pylori + ve cases } \\
\mathrm{N}=50\end{array}$} & \multirow[t]{2}{*}{ p-value } \\
\hline & No. & $\%$ & No. & $\%$ & \\
\hline \multicolumn{6}{|c|}{ Child Pugh score: } \\
\hline $\begin{array}{l}\mathrm{A} \\
\mathrm{B}\end{array}$ & 24 & 48.0 & 23 & 46.0 & 0.841 \\
\hline B & 26 & 52.0 & 27 & 54.0 & \\
\hline
\end{tabular}

There was no significant relation between $\mathrm{H}$. pylori positivity and Cause of cirrhosi and Sex of the studied cases (Table 3).

Table (3): Relation between H. pylori positivity and Cause of cirrhosis, and sex of the studied cases

\begin{tabular}{|c|c|c|c|c|c|}
\hline \multirow[b]{2}{*}{ Variables } & \multicolumn{2}{|c|}{$\begin{array}{c}\text { H.pylori -ve } \\
\text { cases } \\
\mathbf{N}=\mathbf{5 0}\end{array}$} & \multicolumn{2}{|c|}{$\begin{array}{c}\text { H.pylori +ve } \\
\text { cases } \\
\mathbf{N}=\mathbf{5 0}\end{array}$} & \multirow[t]{2}{*}{ p-value } \\
\hline & No. & $\%$ & No. & $\%$ & \\
\hline \multicolumn{6}{|l|}{ Causes } \\
\hline HCV & 37 & 74.0. & 42 & 84.0 & \multirow{3}{*}{0.251} \\
\hline HBV & 11 & 22.0 & 5 & 10.0 & \\
\hline PBC & 2 & 4.0 & 3 & 6.0 & \\
\hline \multicolumn{6}{|l|}{ Sex } \\
\hline Male & 22 & 58.0 & 22 & 44.0 & \multirow[t]{2}{*}{0.0625} \\
\hline Female & 21 & 42.0 & 28 & 56.0 & \\
\hline
\end{tabular}

\section{DISCUSSION}

Regarding sociodemographic data of our participants, there was no statistically significant difference between the two studied groups as regard age and gender. Our results were in agreement with study of Elsebaey et al. (2019) who reported that there was no statistically significant difference between the two studied groups as regard age and gender.

The present study showed that $79 \%$ of causes of cirrhosis were $\mathrm{HCV}$ infection, $15 \%$ was HBV infection, $6 \%$ was due to Primary biliary cirrhosis, and $0 \%$ was alcoholic abuse.
Our results were in line with study of Eid et al. (2016) as they observed that regarding the etiology of cirrhosis among the studied groups. Hepatitis $\mathrm{C}$ was found in $75 \%$ of patients followed by hepatitis $\mathrm{B}$ in $18 \%$, whereas other causes of cirrhosis were $7 \%$. Furthermore, Elsebaey et al. (2019) reported that, regarding the etiology of cirrhosis, $2.27 \%$ of cases had HBV infection. Puri et al. (2017) stated that the overall prevalence of $\mathrm{H}$. pylori in all patients with liver cirrhosis was $55 \%$, Safwat et al. (2015) found prevalence of $60 \%$. Abbas et al. (2014) found prevalence of $62.1 \%$. Yet, a lower seroprevalence $(35.7 \%)$ was reported by 
Sathar et al. (2013). This discrepancy could be attributed to the different tools of $\mathrm{H}$. pylori diagnosis as they depend on anti-H. Pylori IgG serology.

As regard Child Pugh score, our results showed that there was no significant difference between the studied cirrhotic groups as regard Child Pugh score. There was no significant relation between $\mathrm{H}$. pylori positivity and Child Pugh score of the studied cirrhotic cases.

Our results were in agreement with study of Sakamoto et al. (2013) as they reported that there was no significant difference between the bleeding and nonbleeding groups in hepatic functional reserve assessed by Child-Pugh score.

In contrast to our study, Elsebaey et al. (2019) found that there was significant difference regarding Child-Pugh class. Pogorzelska et al. (2017) stated that irrespective of the cause of cirrhosis, $27 \%$ patients were graded as Child-Pugh class A, $47 \%$ as Child-Pugh class B, and $26 \%$ as Child-Pugh class C. Class $\mathrm{C}$ included mostly patients with alcoholic liver cirrhosis $(41 \%)$.

Puri et al. (2017) reported that according to CTP classification, patients were classified as Child A 50\%, Child B $35 \%$, and Child C 15\%. Patients with PHG and H. pylori infection, $65.3 \%$ had severe PHG, whereas $30.8 \% \mathrm{H}$. pylori-negative patients had severe PHG. Reflecting a significant relation between the infection and severity of PHG.

In the present study, there was no significant relation between $H$. pylori positivity and Cause of cirrhosis.

In contrary of our results, Pogorzelska et al. (2017) observed that incidence of $\mathrm{H}$. pylori infection among people infected with $\mathrm{HCV}$ or $\mathrm{HBV}$ was significantly higher (60.9-67.7\%). These observations comply with the research by Hanafy et al. (2016) who have demonstrated H. pylori infection in $70 \%$ of patients chronically infected with $\mathrm{HCV}$.

Wang et al. (2016) demonstrated that the highest proportion of patients with $\mathrm{H}$. pylori infection in the group of those who are $\mathrm{HCV}$ positive can be detected in the case of hepatocellular carcinoma (HCC) development. It seems that very frequent confection with $\mathrm{H}$. pylori and $\mathrm{HCV}$ among people with HCC may contribute to increased incidence of this tumor, because $\mathrm{HCV}$ and $\mathrm{H}$. pylori are deemed to be carcinogenic. Unfavorable effect of $\mathrm{H}$. pylori infection among patients with $\mathrm{HCV}$ may be diverse. In the past, eradication of these bacteria led to increased platelet number, which allowed administration of antiviral treatment (with interferon).

On investigating the relation between H. pylori and PHG in cirrhotic patients, Puri et al. (2017) found a higher prevalence of the infection among patients with rather than those without PHG $(67 \%$ vs. $33 \%$ ). In addition, a significant association was found between $\mathrm{H}$. pylori and PHG as an independent risk factor. Similarly, study of Sathar et al. (2013) showed a significant association between H. pylori and PHG. On the contrary, other studies suggested that $\mathrm{H}$. pylori infection was unlikely to contribute in the pathogenesis of PHG (Puri et al., 2017).

Our results showd that there was a significant relation between $H$. pylori positivity and Sex of the studied cases. The results were supported by study of Puri et al. (2017) who stated that H. pylori 
increase obviously in cases with portal hypertension thus may play a role in the development of PHG. The socioeconomic status of the studied patients may have an impact on this difference. In addition, it has been postulated that PHG does not provide an adequate environment for $\mathrm{H}$. pylori colonization. And, therefore, this organism does not add significantly to the occurrence of PHG (Huang et al., 2017).

\section{CONCLUSION}

There was a significant association between $H$. pylori infection and non variceal upper gastrointestinal bleeding. Thus, eradication therapy has a role in reducing the incidence of NVUGIB in cirrhotic patients. Avoiding risk factors, early diagnosis and treatment of peptic ulcer in cirrhotic patients are important to prevent complications and must be emphasized to all physicians.

Conflicts of interest: No conflicts of interest were encountered.

Acknowledgement: The authors are grateful for the patients without whom this study would not have been done.

\section{REFERENCES}

1. Abbas, Z., Yakoob, J. and Usman, MW. (2014): Effect of Helicobacter pylori and its virulence factors on portal hypertensive gastropathy and interleukin (IL)-8, IL-10, and tumor necrosis factor-alpha levels. Saudi Journal of Gastroenterology, 20: $120-7$.

2. Eid, KAA., Shawky, MAE. and Hassan, AM. (2016): Prevalence of Helicobacter pylori infection in patients with portal hypertensive gastropathy owing to liver cirrhosis in Upper Egypt. Al-Azhar Assiut Medical Journal, 14(3): 109-111.
3. Elsebaey, MA., Tawfik, MA. and Elshweikh, SA. (2019): Impact of Helicobacter pylori Infection on Gastric Variceal Bleeding among Patients with Liver Cirrhosis. Gastroenterol Res Pract., 6:529-532.

4. Hanafy, AS., El Hawary, AT. and Hamed EF. (2016): Impact of Helicobacter pylori eradication on refractory thrombocytopenia in patients with chronic $\mathrm{HCV}$ awaiting antiviral therapy. European Jourrnal of Clinical Microbiology Infectious Diseases, 7:11711176.

5. Hassan, A., Afaf, T., Hanaa, M. and Ashraf, A. (2018): Association of Helicobacter pylori infection and Potal Hypertensive Gastropathy in Liver Cirrhosis. The Medical Journal of Cairo University, 86:1281-1286.

6. Holland-Bill, L., Christiansen, C., Gammelager, $H$. and Mortensen, R. (2015): Chronic liver disease and 90-day mortality in 21359 patients following peptic ulcer bleeding - a Nationwide Cohort Study. Alimentary Pharmacology and Therapeutics, 41(6):564-72.

7. Huang, J. and Cui, J. (2017): Evaluation of Helicobacter pylori in patients with chronic hepatic disease. Chinese medical journal, 130(2):149-156.

8. Kitano, S. and Dolgor, B. (2012): Does portal hypertension contribute to the pathogenesis of gastric ulcer associated with liver cirrhosis? J Gastroenterol., 35:79-86.

9. Narayanan, M., Reddy, K., Mrasicano, E. and Kavya, M. (2018): Peptic Ulcer Diseas and Helicobacter pylori infection. Missouri medicine, 115(3):219-222.

10.Pogorzelska, J., Lapińska, M., Kalinowska, A., Lapinski, T. and Flisiak, R. (2017): Helicobacter pylori infection among patients with liver 
cirrhosis. European Journal of Gastroenterology \& Hepatology, 29(10): 1161-1164.

11.Puri, S., Jain, M. and Narayan, KS. (2017): Helicobacter pylori infection in patients with portal hypertensive gastropathy owing to liver cirrhosis: Prevalence and relation with severity of gastropathy. Journal of Digestive Endoscopy, 8(03): 123-128.

12.Safwat, E., Hussein, HA. and Hakim, SA. (2015): Helicobacter pylori in Egyptian patients with $\mathrm{HCV}$-related liver cirrhosis and portal hypertensive gastropathy: Prevalence and relation to disease severity. Life Sci J., 12:168-73.

13.Sakamoto, Y., Oho, K. and Toyonaga, A. (2013): Effect of Helicobacter pylori infection on esophagogastric variceal bleeding in patients with liver cirrhosis and portal hypertension. Journal of Gastroenterology and Hepatology, 28(9): 1444-1449.
14.Sathar, SA., Kunnathuparambil, SG. and Sreesh, S. (2013): Helicobacter pylori infection in patients with liver cirrhosis: Prevalence and association with portal hypertensive gastropathy. Annals of Gastroenterology, 26(4):48-52.

15.Toyonaga, A. and Iwao, T. (2013): Portal hypertensive gastropathy. J Gastroenterol Hepatol., 13:865-877.

16.Voulgaris, t., karagiannakis, D., Siakavellas, S., Kalogera, D., Angelopoulos, T., Chloupi, E.and Vlachogiannakos, j. (2019): High prevelance of asymptomatic peptic ulcers diagnosed during screening endoscopy in pateints with cirrhosis. Annals of Gastroenterology, 32(5):451-453.

17.Wang, J., Li, WT. and Zheng, YX. (2016): The association between Helicobacter pylori infection and chronic hepatitis C: a meta-analysis and trial sequential analysis. Gastroenterol Res Pract., 8:780-795. 
تأثير عدوى الميكروب الحلزونى على النزيف الغير مسبب بالدو الى للمرضى الذئين يعانون من تليف بالكبد

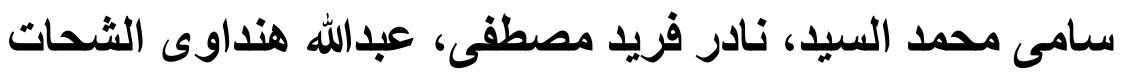
قسم أمراض الكبل والجهاز الهضمى والأمراض المعدية كلية الطب، جامعة الأزهر

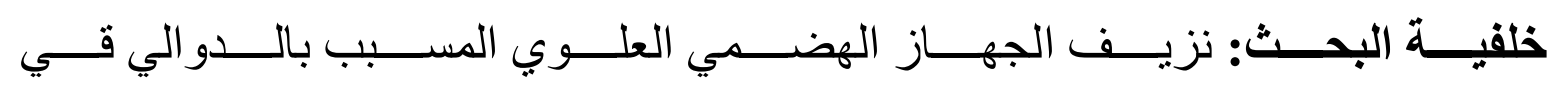

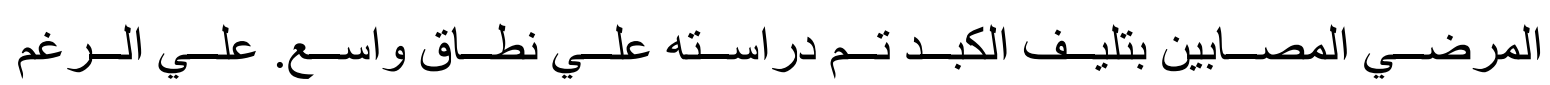

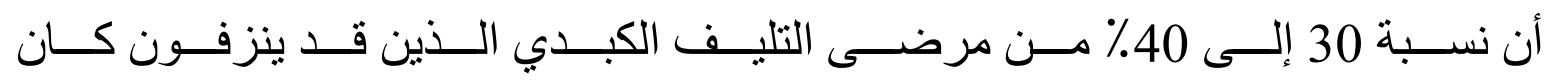

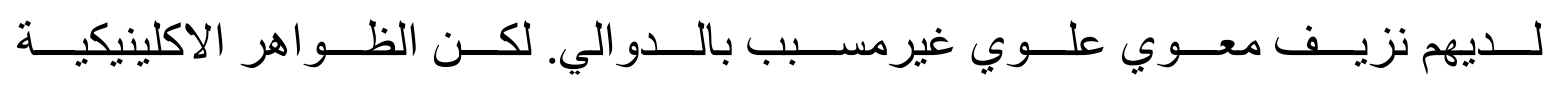
ونتائج المنظار نادرا مايتم الابلاغ عنها لهؤلاء المرضي.

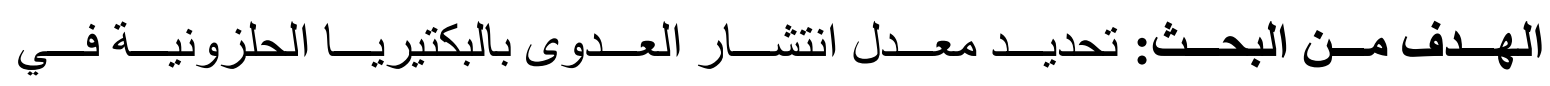

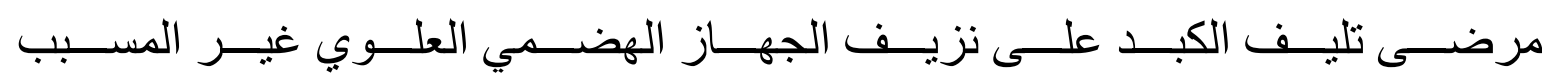

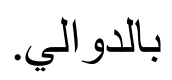

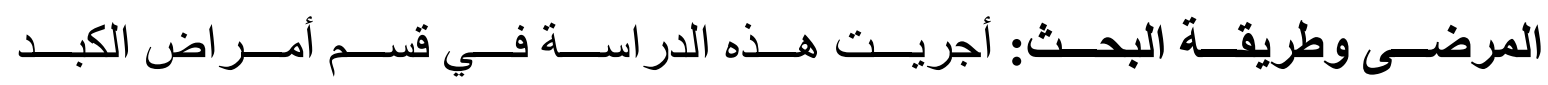

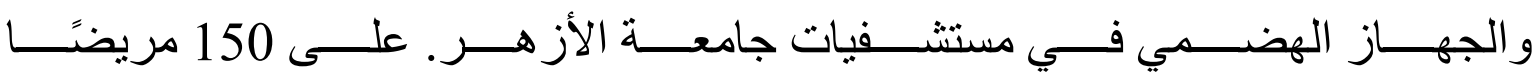

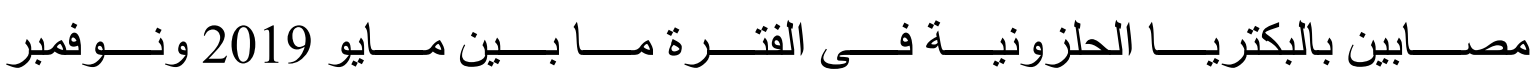

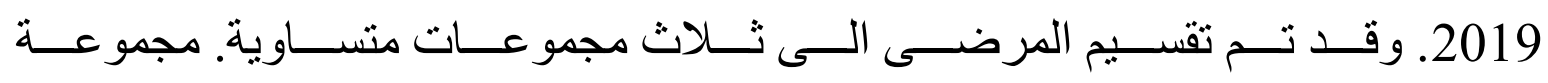

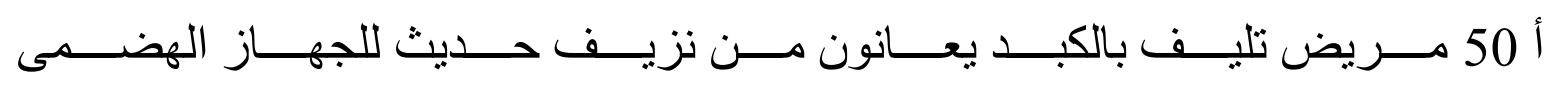

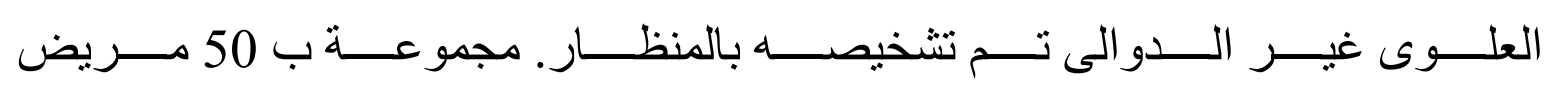

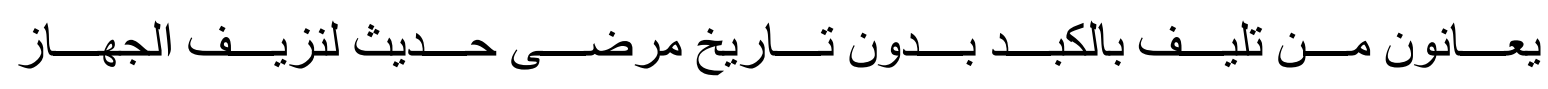

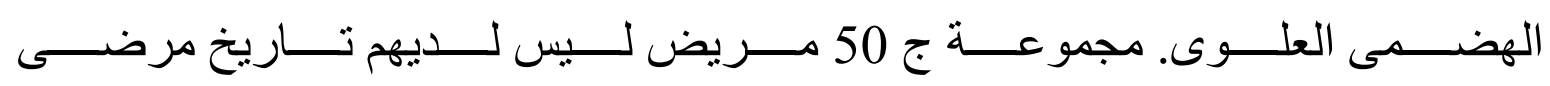

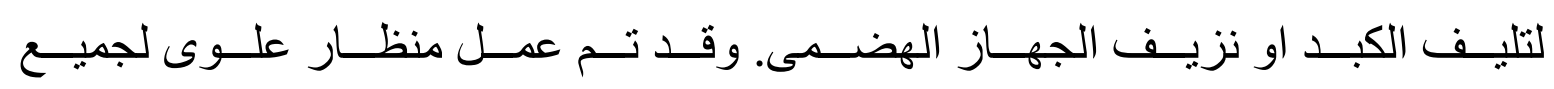
المرضى وأخذ عينات من المعدة للفحص المجهرى. 


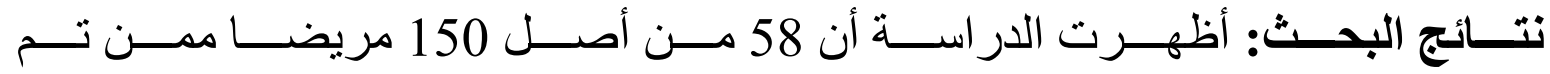

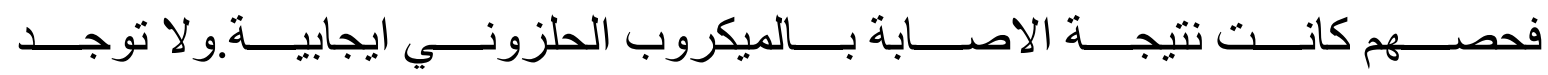

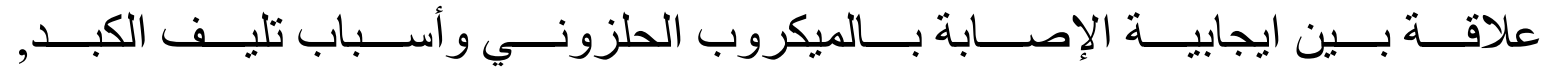

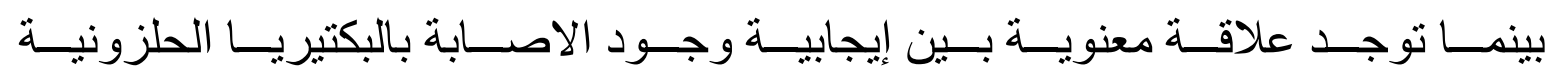

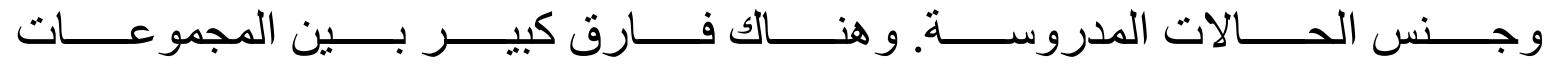
المدروسة فيما يتعلق بتوزيع وجود الميكروب الحلزوني.

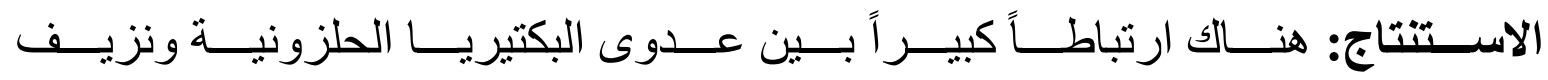

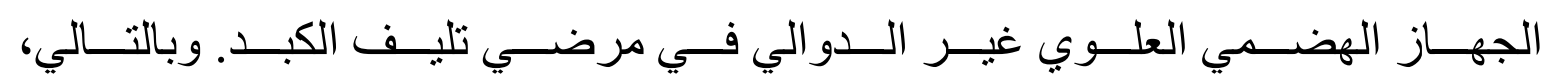

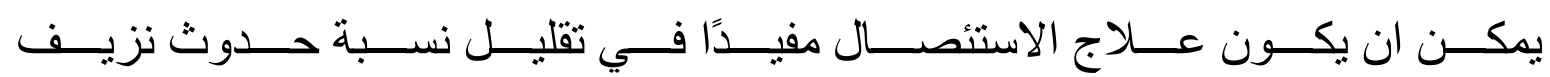
الجهاز الهضمي العلوي غير الدوالي. 